\title{
Using Computer Technology to Foster Learning for Understanding
}

\author{
ELAINE VAN MELLE ${ }^{1 *}$ AND LEWIS TOMALTY ${ }^{2}$ \\ Faculty of Education ${ }^{1}$ and Department of Microbiology and Immunology, ${ }^{2}$ Queen's University at Kingston, \\ Kingston, Ontario, Canada K7M $3 G 7$
}

The literature shows that students typically use either a surface approach to learning, in which the emphasis is on memorization of facts, or a deep approach to learning, in which learning for understanding is the primary focus. This paper describes how computer technology, specifically the use of a multimedia CD-ROM, was integrated into a microbiology curriculum as part of the transition from focusing on facts to fostering learning for understanding. Evaluation of the changes in approaches to learning over the course of the term showed a statistically significant shift in a deep approach to learning, as measured by the Study Process Questionnaire. Additional data collected showed that the use of computer technology supported this shift by providing students with the opportunity to apply what they had learned in class to order tests and interpret the test results in relation to specific patient-focused case studies. The extent of the impact, however, varied among different groups of students in the class. For example, students who were recent high school graduates did not show a statistically significant increase in deep learning scores over the course of the term and did not perform as well in the course. The results also showed that a surface approach to learning was an important aspect of learning for understanding, although only those students who were able to combine a surface with a deep approach to learning were successfully able to learn for understanding. Implications of this finding for the future use of computer technology and learning for understanding are considered.

One of the hallmarks of the new science of learning is its emphasis on learning with understanding, in which the goal of education is to produce learners who are better able to transfer what they have learned to new problems and settings (6). Students who learn for understanding are characterized in the literature as using a deep approach to learning (2). These are students who focus on the underlying meaning: on main ideas, themes, principles, or successful applications of knowledge. This is in contrast to a surface approach, in which students focus on memorizing selected content, usually for the purposes of academic assessment.

The terms "deep" and "surface" were first formally introduced in 1976 by Marton and Saljo, who, on the basis of an analysis of student responses to questions posed after reading a passage of prose, identified two clearly distinguishable levels of information processing (23). These were described as follows:

In the case of surface-level processing the student directs his attention towards learning the text itself (the sign), i.e., he has a "reproductive" conception of learning which means that he is forced to keep to a rote-learning strategy. In the case of deep-level processing, on the other hand, the student is directed towards the intentional content of the learning material (what is signified), i.e., he is directed towards comprehending what the author wants to say about, for instance, a certain scientific principle or problem. (p. 7)

Since then a substantial body of research has created a high degree of consensus on the two approaches to learning, to the point where the terms are commonly used to describe learning in higher education $(2,25)$. It is important to note

*Corresponding author. Phone: (613) 545-9441. E-mail: 6mepv@qlink.queensu.ca. that student approaches to learning are distinct from learning styles in that learning styles refer to predefined, permanent, personal dispositions and as such are neither negotiable nor sensitive to context $(2,14)$. On the other hand, there are a number of studies which suggest that student approaches to learning are quite sensitive to, and can be influenced by, teaching context $(1,12,13,21,24,26)$.

\section{COMPUTER TECHNOLOGY AND STUDENT APPROACHES TO LEARNING}

There is evidence to suggest that the introduction of computer technology can have profound effects on how students approach learning. For example, Reil found that working in groups around the computer allowed the students to move beyond focusing on basic information to more global issues (27). Ruberg, Moore, and Taylor also found that computerbased interactive activities provided students with an opportunity to construct meaning by taking time to put their newly learned concepts into their own words (28). Mandinach and Cline showed that the use of computer technology engaged students in problem solving, leading to a deeper understanding of content and context (22). Finally, Jacobson and Spiro found that using hypertext to present material in a number of different ways supported superior transfer of knowledge (17).

\section{INTEGRATING COMPUTER TECHNOLOGY INTO THE MICROBIOLOGY CURRICULUM}

Microbiology 121 is one of five required courses for 70 first-year nursing students at Queen's University. Computer technology was integrated into the microbiology curriculum in two steps. First, the entire course curriculum was reorganized to support learning for understanding. The basic facts 
TABLE 1. Microbiology 121 course organization, representing a blending of instructional design and current understanding of complexity in thinking

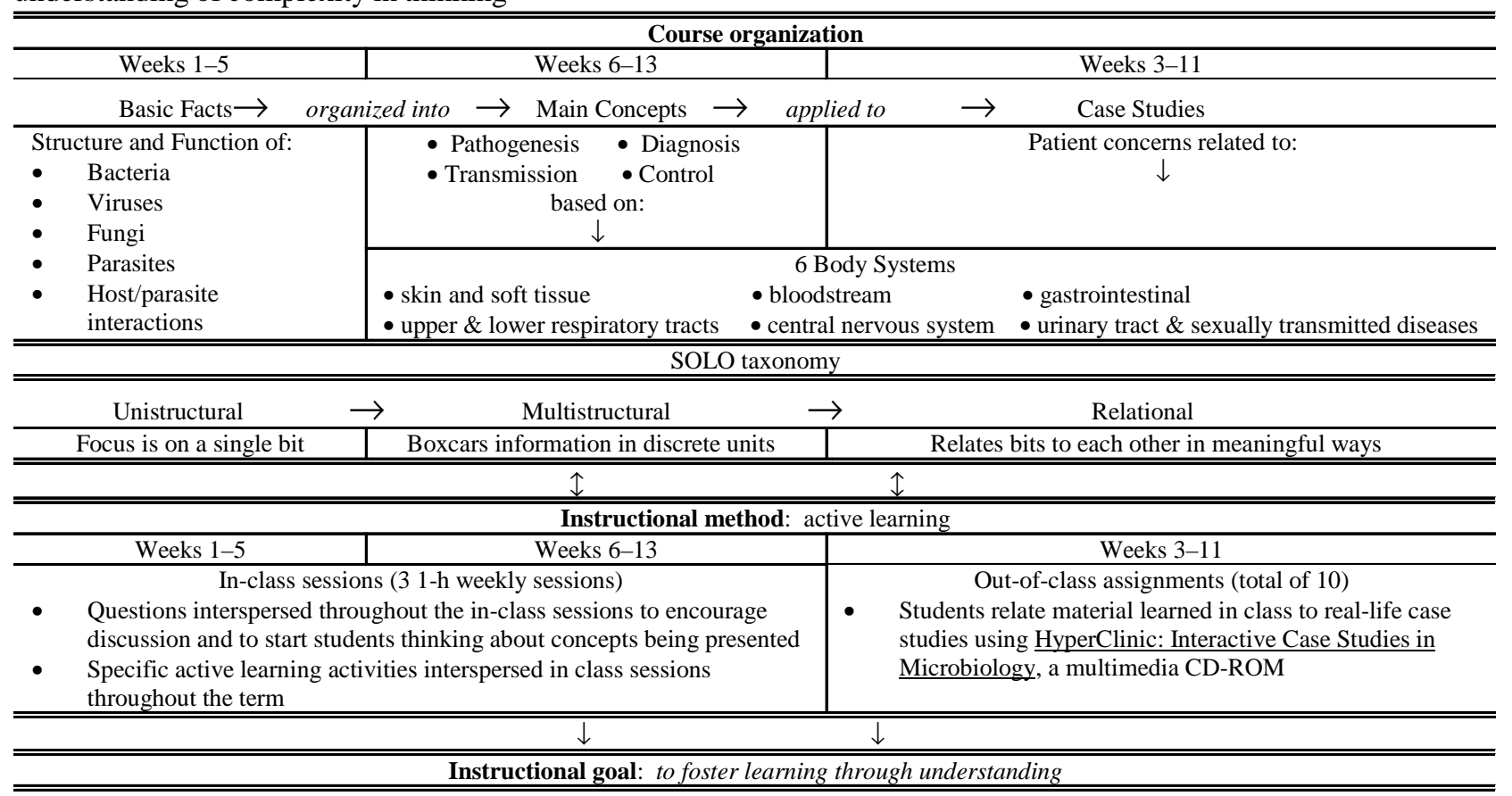

(e.g., structure and function of the cell envelope), presented at the beginning of the course, were used as a foundation for the introduction of main concepts (e.g., pathogenesis). In turn, students were required to apply the concepts to case studies (Table 1). This was a significant change from the previous curriculum, in which the focus was primarily on the presentation of facts about specific microorganisms (e.g., which microorganisms cause which diseases).

As the second step, active learning was adopted as the primary instructional strategy since people who become active learners are better prepared to transfer what they have learned to new problems and settings (6). Active learning was defined as "a teaching strategy that uses one or more course resources to ensure elements of student activity," where elements of activity can include talking, reading, writing, reflecting, or doing (8). In class, discussions were used as a primary active learning strategy. Out of class, computer technology was used as a resource to support active learning.

A CD-ROM called HyperClinic: Interactive Case Studies in Microbiology had been specifically developed by the instructor and a colleague as a tool to facilitate problem-based learning. In HyperClinic, as with the overall course material, the cases were organized according to body systems (Fig. 1). On a weekly basis, students were provided with assignment questions which would direct them to a specific body syssystems. tem and a particular case study. Students were then required to interact with the program, applying what they had learned in class, to choose specimens, order tests, and interpret the test results in order to answer questions posed about the case study. As part of the process, students could receive feedback about their choice of and/or interpretation of lab tests. For example, the program provided feedback on whether the test selection was correct and if not, why not. Students could also access information about the basic microbiology of the

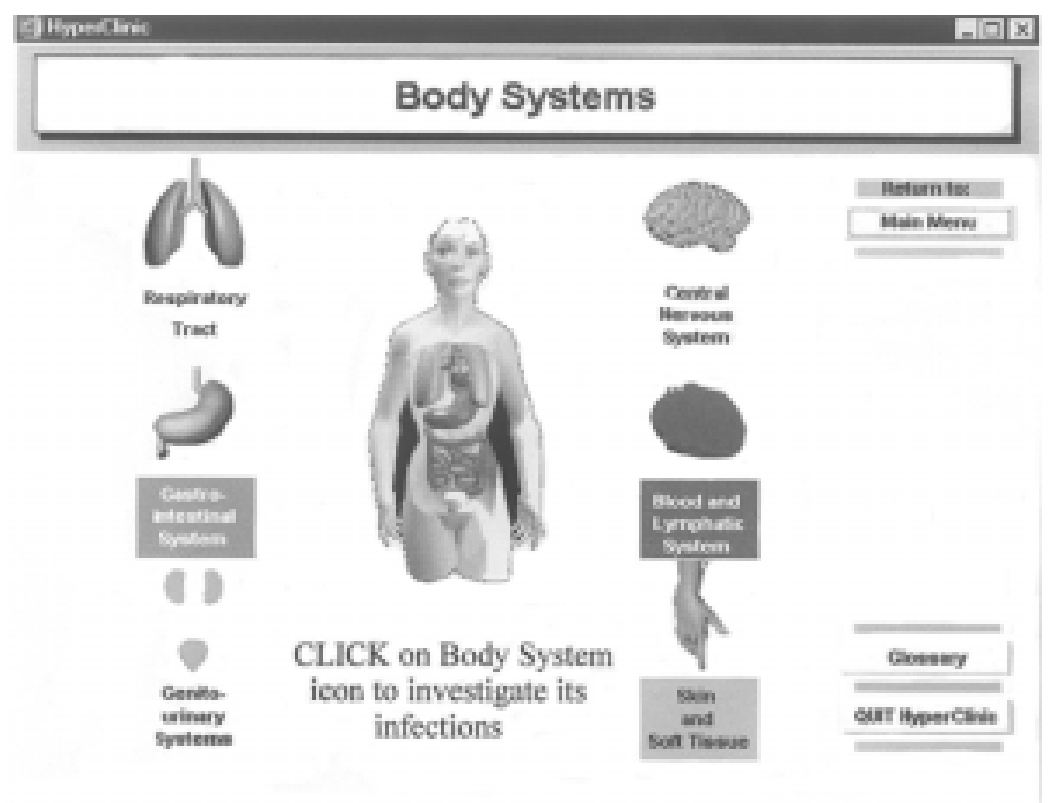

FIG. 1. HyperClinic: Interactive Case Studies in Microbiology is a multimedia CD-ROM in which case studies are organized according to body 
case as well as specifics about the correct laboratory testing procedure.

As a multimedia CD-ROM, all information in $\underline{\text { HyperClinic }}$ was presented as a combination of video, text, animations, pictures, graphics, and sound. A key feature of the software was the hyperlink feature, which allowed students to access detailed information not just in relation to case studies, but also in relation to specific diagnostic tests or microorganisms, with a simple click of the mouse, no matter where they were in the program. Also included was the ability to access relevant Internet sites at specific points in the program. Consequently, it was felt that HyperClinic contained sufficient information to support the material learned in class, and it was designated as the only required resource for the course.

The course reorganization shared similar features with the Structure of the Observed Learning Outcome, or SOLO, taxonomy (5). SOLO provides a systematic way of describing how a learner's performance grows in complexity when many academic tasks are being mastered. Progression through the levels implies an increase in knowledge as well as a deepening of understanding of the course material. Although the full model describes five levels, the reorganization of the microbiology course paralleled the middle three levels of the SOLO taxonomy (Table 1). The SOLO taxonomy is based on a study of learning outcomes and emphasizes the importance of matching the evaluation of learning outcomes to the design of the curriculum. Consequently, the assessment method was also changed to support the focus of learning through understanding.

To summarize, the course was reorganized so that students would learn not just basic facts about microorganisms, but also the main concepts in the field and how those concepts applied to the practice of nursing. The changes were made to foster student learning through understanding in order to enhance retention and the ability to apply the material. Active learning was used as the primary instructional strategy.

\section{RESEARCH QUESTION}

Based on the review of the literature and curriculum changes, the following question was formulated to guide the evaluation of the use of computer technology in the course: to what extent did the use of computer technology facilitate a deep approach to learning?

\section{RESEARCH METHODS}

Postsecondary learning is not usually conducted in wellstructured, uniform, or stable environments. This makes it difficult to use a strictly experimental, quantitative approach when evaluating the use of computer technology, due to the lack of a well-defined traditional method to serve as a stable comparison (11). Consequently, a case study approach was chosen. A case study allows for the thorough investigation of a phenomenon within its real-life context because data collection and analysis are guided by the questions posed by the investigator, rather than a fixed predetermined formula
(30). For the purposes of this study, the following combination of quantitative and qualitative data was collected.

The Study Process Questionnaire (SPQ) designed by Biggs was used to gather data on student approaches to learning (4). This tool was chosen because the SPQ had been used widely in learning in a variety of systems of higher education. This included use of the SPQ to monitor student progress in the same way that the results would be used in this study (20). The questionnaire contained 14 questions representing a deep approach to learning, (e.g., "I find that I have to do enough work on a topic so that I can form my own point of view before I am satisfied") and 14 questions representing a surface approach to learning (e.g., "I learn some things by rote, going over and over them until I know them by heart"). Students were required to respond on a five-point Likert scale, with 1 representing "never or rarely true" and 5 indicating "always or almost always true." Therefore, students received a score ranging from 14 to 70 points for both the deep and the surface scale, where the lower the score, the less a particular approach to learning was preferred by the individual student. Students were requested to complete the SPQ twice over the course of the term: on the first day of classes and again at the end of the term.

A Student Background Questionnaire was used to gather information in relation to individual student background variables. A Student Satisfaction with Computer Technology Questionnaire was created to capture feedback to the use of computer technology. Information was gathered at the beginning and at the end of the term, respectively.

Interviews were used to gather in-depth information about how students used computer technology to support their learning process over the course of the term. Interviews were chosen because they are an effective way to make explicit the thoughts and approaches of the participants, particularly in cases where the participants themselves are not always aware of how they experience a given situation (29). Recognizing that students may experience learning in the course in different ways, different combinations of their reported frequency of computer use (high versus low) and their SPQ score on the deep scale coming into the course (high versus low) were used to select students to be interviewed. Consequently, a total of eight students were interviewed (two for each possible combination), three times each, over the course of the term.

Given the extensive data to be collected, it was important to ensure that the research study would not impact on the students in any way. Consequently, students were given the option not to participate, or to withdraw, at any point during the study. Of the 70 students in the class, only 1 chose not to participate in the study.

\section{RESULTS: DID THE USE OF COMPUTER TECHNOLOGY FACILITATE A DEEP APPROACH TO LEARNING?}

There was a statistically significant rise $(P<0.01)$ in the mean of the deep approach to learning scores, as measured 
through the SPQ, from the beginning to the end of the term. The level of increase was uniform across the entire class, since the significant increase in deep scores represented an expected regression to the mean (Fig. 2). Examination of individual questions within the deep scale revealed an interesting finding. Four of the 14 questions captured the extent to which students related the material to real-life situations, or to what they already knew, as part of their approach to studying. For example, one of the four questions read, "While I am studying, I often think of real-life situations to which the material that I am learning would be useful." The responses to these four questions were primarily responsible for the significant rise in the deep scale score throughout the class. The next step was to see the extent to which the use of computer technology contributed to these findings.

Examination of the interview data indicated that the students used HyperClinic to relate material to what was learned in class or to real-life situations. The following quotes illustrate typical responses indicating how students actually used HyperClinic as part of their learning process:

- When I have to work with the CD-ROM I have to keep thinking where do I want to go in order to get from this bacteria to the information I need. I move things around from one system to the next and I actually have to sift through things to get answers. I find that better because you know where the answers are coming from. It keeps you relating things back and you keep applying why...so it [HyperClinic] kind of links it subconsciously for you.

(Lee, interview 1.)

- It's like a really deep process because when I go into the ordering tests and I get the test wrong, then I'll click on the right side and find out what's the reason behind this test and so then I'll understand why you order tests for that particular situation and therefore it makes sense when it comes to analyzing results so I can understand not just the question but what I am learning.
(Cathy, interview 1.)

The results of the interview data were supported by the class responses to the Student Satisfaction Questionnaire, in which $73 \%$ of the class found HyperClinic helpful or very helpful to their learning in the course. Of the additional comments provided by students, $25 \%$ said that the case studies and real application of material facilitated understanding or helped to put the whole picture together.

Influence of individual differences. All students interviewed, regardless of the predefined selection variables, reported that HyperClinic facilitated their understanding of the course material. During the interview process, however, it became apparent that the students were using different strategies to answer the assignment questions. Some students described "guessing at answers," which meant formulating a response based on the available information. Other students described using a "common sense approach" in which material from their course notes was clearly used in conjunction with the material on the CD-ROM to formulate an answer. Interestingly, the students using the common sense strategy had transferred in to the nursing course after completing one year of university. The other students had entered the nursing program immediately after completion of high school. Consequently, it was decided to explore the influence of educational background variables on student approaches to learning and performance in the course.

Data was analyzed based on two specific items: (i) whether students were recent high school graduates and (ii) their previous exposure to a microbiology course. To make sure that the groups were comparable, only complete data sets were used. Of the 55 students included in the analysis, $27(49 \%)$ were recent high school graduates. For the remaining 28 students, the time out of school ranged from 1 to 26 years, with the average being 6 years. Of this group, 7 students had a previous course in microbiology. (Note that these students were not taking the course for the second time;

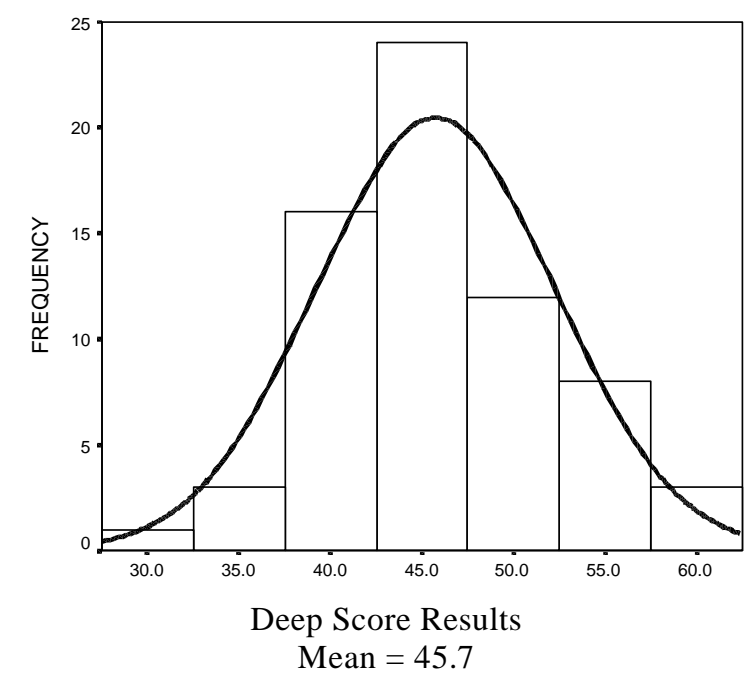

(a) beginning of the term (SPQ1) $(n=67)$

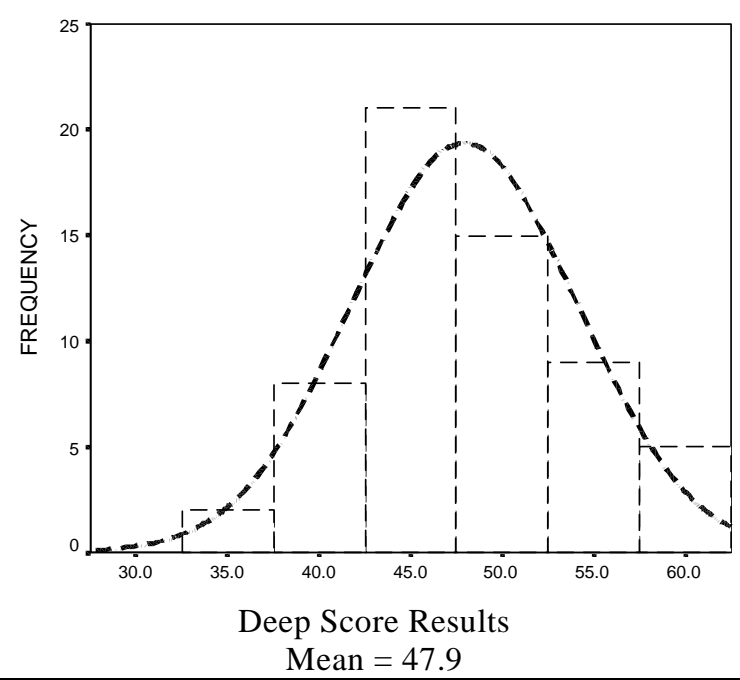

(b) end of the term (SPQ2) $(n=60)$

FIG. 2. Histograms of SPQ deep score results at the beginning of the term (SPQ1) (a) and at the end of the term (SPQ2) (b). 
rather, this group was made up of students who had taken a previous course in microbiology before transferring into the nursing program.) As a result of this categorization, three distinct groups of students emerged: group 1, students with a previous course in microbiology; group 2, students who were not recent high school graduates; and group 3, students who were recent high school graduates (Table 2).

Although all three groups showed an increase in deep scores, the only statistically significant increase was exhibited by students who were not recent high school graduates (group 2) $(P<0.001)$. This group also performed significantly better in the course than the other two groups (Table 2). Students in groups 1 and 3 had a statistically significant higher surface score coming into the course than students in group $2(P<0.01)$. Students in group 1 , who were familiar with the subject area, performed slightly better in the course overall than the students who were recent high school graduates (group 3), but the difference was not statistically significant. Interestingly, there was also a rise in surface scores over the course of the term, to the point where there was no significant difference between the three groups in surface scores by the end of the term. The only group for whom the rise in surface score was not statistically significant was group 1 (students with a previous course in microbiology).

\section{DISCUSSION}

This study showed that the use of computer technology did play a role in facilitating a deep approach to learning over the course of the term. Specifically, students reported using concepts learned in class to interact with the CD-ROM in order to answer questions about the case studies. Individual differences seemed to influence the extent to which students adopted a deep approach to learning; students with a predisposition to a surface approach to learning did not show an increase in deep approaches to learning. The finding is consistent with the model proposed by Kember and Gow, who identify a predisposition to a surface approach to learning as a significant barrier when trying to facilitate a deep approach, or learning for understanding (20). Furthermore, the extent of the impact is emphasized by the finding that a predisposition to a surface approach to learning seemed to be more influential in determining performance in the course than having had a previous course in microbiology.

The influence of a student's approach to learning coming into the course also illustrates the point made by Jacobson and Spiro that a student's stage of learning is a key variable with respect to the effective use of computer technology (18). Their argument implies that the use of a hypermedia program may have been too advanced for some of the students in the class, and alternatively a drill-and-practice program may have been a better match for students with a predisposition to a surface approach to learning. However, Jacobson and Spiro also describe the importance of matching the nature of the subject area with use of technology. For example, well-structured knowledge areas, such as mathematics, may

TABLE 2. Student groupings based on educational background variables, SPQ results, and performance in the course

\begin{tabular}{|c|c|c|c|c|c|c|c|}
\hline \multirow[t]{3}{*}{ Parameter } & & \multicolumn{6}{|c|}{ Result } \\
\hline & & \multicolumn{2}{|c|}{$\begin{array}{l}\text { Group 1 }(n=7) \\
\text { (previous course } \\
\text { in microbiology) }\end{array}$} & \multicolumn{2}{|c|}{$\begin{array}{l}\text { Group } 2(n=21) \\
\text { (not recent high } \\
\text { school graduates) }\end{array}$} & \multicolumn{2}{|c|}{$\begin{array}{c}\text { Group 3 }(n=27) \\
\text { (recent high school } \\
\text { graduates) }\end{array}$} \\
\hline & & Mean & SD & Mean & SD & Mean & SD \\
\hline \multicolumn{8}{|l|}{$\overline{\mathrm{SPQ}}$} \\
\hline \multirow[t]{3}{*}{ Deep score } & SPQ1 & 47.9 & 8.23 & 45.5 & 6.05 & 46.0 & 6.37 \\
\hline & SPQ2 & 48.3 & 8.73 & 48.6 & 5.85 & 47.3 & 6.25 \\
\hline & SPQ2 - SPQ1 & 0.40 & 3.45 & $3.1 * * * a$ & 3.59 & 1.2 & 4.00 \\
\hline \multirow[t]{3}{*}{ Surface score } & SPQ1 & 52.4 $*^{b}$ & 5.50 & 44.7 & 7.75 & 51.1**b & 5.44 \\
\hline & SPQ2 & 52.6 & 4.65 & 48.4 & 9.41 & 53.0 & 6.07 \\
\hline & SPQ2 - SPQ1 & 0.14 & 5.55 & $3.7 * * a$ & 6.00 & $1.9^{*^{a}}$ & 4.42 \\
\hline \multicolumn{8}{|l|}{ Grades $^{c}$} \\
\hline \multicolumn{2}{|l|}{ Assignment } & 22.2 & 1.89 & $24.0 * *$ & 2.20 & 21.8 & 2.00 \\
\hline \multicolumn{2}{|l|}{ Midterm } & $13.6 * *$ & 2.59 & $16.2 * *$ & 1.69 & 14.2 & 1.90 \\
\hline \multicolumn{2}{|l|}{ Final exam } & 34.9 & 7.01 & $37.0 * *$ & 6.57 & 30.8 & 7.56 \\
\hline \multicolumn{2}{|l|}{ Course } & 71.1 & 9.82 & $77.7 * * *$ & 9.12 & 67.1 & 9.00 \\
\hline
\end{tabular}

${ }^{a}$ Level of significance (two-tailed paired-samples $t$ test): $*, P<0.05 ; * *, P<0.01 ; * * *, P<0.001$.

${ }^{b}$ Level of significance (one-way analysis of variance [ANOVA]): $*, P<0.05 ; * *, P<0.01$.

${ }^{c}$ Level of significance (one-way ANOVA): **, $P<0.01 ; * * *, P<0.001$. 
be best suited to computer-based drill systems. According to their framework, since microbiology is not a well-structured knowledge area, hypertext is an appropriate learning tool to use. In addition, the fact that a previous course in microbiology did not make a significant difference to performance in the course suggests that there is more to the issue of fostering learning for understanding than simply reconsidering the use of computer technology.

Kember and Gow suggest that the transition to a deep approach to learning is particularly difficult for students with a predisposition to a surface approach to learning, and therefore these students require more help in making the transition. For example, teaching appropriate skills and reorienting concepts of knowledge are suggested as potential strategies (20). The explicit introduction of learning strategies as a way of fostering learning for understanding is supported by Bruer, who makes the distinction between expert and lessskilled learners (7). To set the scene for the introduction of learning strategies, the differences between the two categories of learners are worth exploring further. This differentiation will also help to explain the observed increase in surface approaches to learning.

Bruer describes a skilled learner as someone who has a very keen awareness that different skills and strategies may be required depending upon the learning situation. Consequently, they do not necessarily rely on a specific approach to learning but are able to adapt their approach in accordance with the demands of the learning situation. The rise in both deep and surface learning scores of the students who were not recent high school graduates supports that this group was able to integrate both surface and deep approaches to learning, as required. This finding makes sense since acquiring basic facts was an important part of the learning process in the reorganized curriculum.

The need to acquire basic facts was also reflected in the rise in surface scores of the students who were recent high school graduates. These students, however, did not show a rise in a deep approach to learning. This pattern is consistent with Bruer's description of less-skilled learners as individuals who are not able to appreciate the difference between memorization and comprehension. Consequently, in a learning situation these students tend to rely primarily upon a surface approach to learning.

The learning profile of students with a previous course in microbiology also resembled that of the group of "unskilled learners," which again helps to explain why this group of students did not do as well in the course, despite their previous exposure to the subject area. In fact, since a surface approach to learning tends to arise as a result of an academic learning environment, if learning in their previous course had been based on memorizing facts about microorganisms, it is possible that previous exposure to the subject area may have been detrimental to their ability to learn for understanding (3). Without additional information, further speculation is not possible. The preceding discussion clearly supports the importance of helping students to develop appropriate strategies when learning for understanding.
This direction is also consistent with the recommendations made by Andrews, Garrison, and Magnusson (1). The authors found that although developmental level may have contributed to first-year students being more surface oriented than third-year students, a stronger argument was made for the influence of the instructional environment in shaping student approaches to learning. Therefore, a logical step might be to make it more apparent to students in the class how computer technology can be used to facilitate learning for understanding.

For example, although students were provided with an introduction to the technology and consistently reminded about the objective of the course, strategies such as how to use the feedback feature available in HyperClinic were not specifically provided. Making the process of learning explicit may be particularly important when hypermedia is used, since merely browsing through the program does not necessarily engender deep enough processing to result in meaningful learning (19). There is a feature inherent in the SOLO taxonomy which further supports the direction of making the learning process more apparent to students in the class.

Biggs and Collis describe transitional responses as a key property of the SOLO taxonomy (5). These responses can occur when the student is feeling ready for the next level but doesn't quite make it. Responses tend to be marked by confusion or inconsistency and typically carry more information than is required. This description parallels how students characterized "guessing" at answers. Perhaps these students were somewhere in the transitional stage moving from facts to understanding. If this is the case, then helping students to become aware of the learning process when using computer technology may facilitate a successful transition.

\section{LIMITATIONS}

The influence of instructional methodology has been put forward as a competing hypothesis when the contribution of computer technology to learning is evaluated (8). For example, in this study it could be argued that the emphasis on active learning, and not necessarily the use of computer technology, was what contributed to the deep approach to learning. To counter this argument, a more thorough analysis of the features of the computer technology and their specific contribution to learning for understanding is required. Jacobson refers to this as "linking theory to design," in which each characteristic of the curriculum is linked to a specific aspect of the learning process (16). This level of detail would also help to clarify the reason for and point at which students may need assistance when learning for understanding.

Using a case study approach has also been faulted for the lack of generalizability, since the study usually involves small sample sizes and is context specific (15). Repeating the cycle of research is one way to address the applicability of the findings. This course of action is also consistent with the recommendation that at least two cycles of research are required in order to fully implement and understand the influence of an educational innovation (21). The need to continue the re- 
search cycle raises the issue of additional instructor workload when this type of instructional innovation is undertaken.

There is no question that the instructor must play a key leadership role. In this study, the role involved developing the CD-ROM, as well as changing the approach to the course. The changes, however, were made over a period of three years. In the first two years, creation of the software was followed by a pilot study. The changes reported in this study were then implemented in the third year, based on the results of the pilot study. The truly essential piece was the ongoing commitment on the part of the instructor. Once this was attained, the issue of workload was addressed by following a cycle of planning, action, observation, and reflection, in an incremental fashion, in accordance with a realistic time frame.

\section{EDUCATIONAL SIGNIFICANCE}

After completing a meta analysis on the effects of hypermedia on learning, Dillon and Gabbard concluded that the most promising direction of research lay in an anlysis of individual learner characteristics and the use of computer technology (10). Although the preliminary nature of this study does not allow for major conclusions to be drawn, it does point to the potential of this line of study when using computer technology to facilitate learning for understanding. Perhaps more importantly, the study also suggests the need to take into account individual student characteristics when implementing curriculum changes to support the new science of learning.

\section{REFERENCES}

1. Andrews, J., D. R. Garrison, and K. Magnusson. 1996. The teaching and learning transaction in higher education: a study of excellent professors and their students. Teaching Higher Educ. 1:81103.

2. Biggs, J. B. (ed.). 1999. Teaching for quality learning at university. The Society for Research into Higher Education and Open University Press, Buckingham, London, England.

3. Biggs, J. B. 1993. What do inventories of student's learning processes really measure? A theoretical review and clarification. Educ. Psychol. 63:3-19.

4. Biggs, J. B. 1987. Study process questionnaire manual. Australian Council for Educational Research, Melbourne, Australia.

5. Biggs, J. B., and K. F. Collis. 1982. Evaluating the quality of learning: the SOLO taxonomy. Academic Press Inc., New York, N.Y.

6. Bransford, J. D., A. L. Brown, and R. R. Cocking (ed.). 1999.

How people learn: brain, mind, experience and school. National Academy Press, Washington, D.C.

7. Bruer, J. T. 1997. Schools for thought: a science of learning in the classroom. The MIT Press, Cambridge, Mass.

8. Cannon, R. April 13, 1999. Personal communication.

9. Clark, R. E. 1994. Media will never influence learning. Educ. Technol. Res. Dev. 42:21-29.

10. Dillon, A., and R. Gabbard. 1998. Hypermedia as an educa- tional technology: a review of the quantitative research literature on learner comprehension, control and style. Rev. Educ. Res. 68:322-349.

11. Ehrmann, S. C. 1995. Asking the right questions: what does research tell us about technology and higher learning? Change March/April:20-27.

12. Franz, J., L. Ferreira, H. Loh, D. Pendergast, M. Service, D. Stormont, L. Taylor, D. Thambiratnam, and B. Williamson. 1996. Students' and lecturers' conceptions of learning in context: an interdisciplinary study. Teaching Higher Educ. 1:325-339.

13. Gow, L., and D. Kember. 1993. Conceptions of teaching and their relationship to student learning. Br. J. Educ. Psychol. 63:2033 .

14. Grasha, A. F. 1996. Teaching with style. Alliance Publishers, Pittsburgh, Pa.

15. Hamel, J., S. Dufour, and D. Fortin. 1993. Case study methods. Sage Publications, Newbury Park, London, England.

16. Jacobson, M. J. 1994. Issues in hypertext and hypermedia research: toward a framework for linking theory to design. J. Educ. Media Hypermedia 3:141-154.

17. Jacobson, M. J., and R. J. Spiro. 1995. Hypertext learning environments, cognitive flexibility, and the transfer of complex knowledge: an empirical investigation. J. Educ. Comput. Res. 12:301-333.

18. Jacobson, M. J., and R. J. Spiro. 1994. A framework for the contextual analysis of technology-based learning environments. J. Comput. Higher Educ. 5:3-32.

19. Jonassen, D. H., and S. Wang. 1993. Acquiring structural knowledge from semantically structured hypertext. J. ComputerBased Instruct. 20:1-8.

20. Kember, D., and L. Gow. 1989. A model of student approaches to learning encompassing ways to influence and change approaches. Instruct. Sci. 18:263-288.

21. Kember, D., and J. McKay. 1996. Action research into the quality of student learning. J. Higher Educ. 67:528-554.

22. Mandinach, E. B., and H. F. Cline. 1996. Classroom dynamics: the impact of a technology-based curriculum innovation on teaching and learning. J. Educ. Comput. Res. 14:83-102.

23. Marton, F., and R. Saljo. 1976. On qualitative differences in learning. I. Outcome and process. Br. J. Educ. Psychol. 46:4-11.

24. Marton, F., and R. Saljo. 1976. On qualitative differences in learning. II. Outcome as a function of the learner's conception of the task. Br. J. Educ. Psychol. 46:115-127.

25. Prosser, M., and K. Trigwell. 1999. Understanding learning and teaching: the experience in higher education. The Society for Research into Higher Education and Open University Press, Buckingham, London, England.

26. Ramsden, P., and N. J. Entwhistle. 1981. Effects of academic departments on students' approaches to learning. Br. J. Educ. Psychol. 54:73-83.

27. Reil, M. 1989. The impact of computers in classrooms. J. Res. Comput. Educ. 22:180-190.

28. Ruberg, L. F., D. M. Moore, and C. D. Taylor. 1996. Student participation, interaction and regulation in a computer-mediated communication environment: a qualitative study. J. Educ. Comput. Res. 14:243-268.

29. Rubin, H., and I. Rubin. 1995. Qualitative interviewing: the art of hearing data. Sage Publishing, Thousand Oaks, Calif.

30. Yin, R. K. 1994. Case study research: design and methods. Sage Publishing, Thousand Oaks, Calif. 